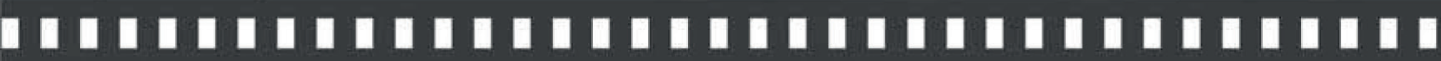

\section{A indicialidade no contexto pós- mídia}

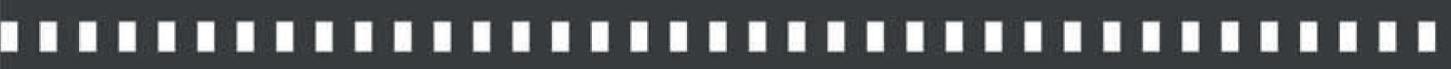

\author{
Eduardo de Jesus
}

Artigo recebido em: 05/05/2017

Artigo aprovado em: 05/06/2017

D0I10.5433/1984-7939.2017v13n22p13 


\title{
A indicialidade no contexto pós-mídia
}

\author{
The indiciality in the post-media context
}

Eduardo de Jesus*

Resumo: $O$ texto traz um breve histórico da inserção da fotografia no domínio da arte e abre um conjunto de reflexões em torno dos meios e suportes na produção artística contemporânea para refletir sobre a indicialidade na produção fotográfica contemporânea. Para tanto articula questões conceituais e tecnológicas em obras atuais para expandir as formas de pensar a indicialidade da fotografia nos regimes imagéticos contemporâneos.

Palavras-chave: Indicialidade. Fotografia Contemporânea. Arte contemporânea.

\begin{abstract}
The text brings a brief history about the insertion of photography in the domain of art and opens a conjunct of reflections around the means and supports in the artistic contemporary production to reflect about the indexiality in the contemporary photographic production. Therefor it articulates conceptual and technological questions in current works to expand the forms of thinking the indexiality of the photography in contemporary imagetic regimes.
\end{abstract}

Keywords: Indiciality. Contemporary photography. Contemporary art.

* Pontifícia Universidade Católica de Minas Gerais. 


\section{Introdução}

Sabemos que ao longo do tempo a fotografia - depois de tantos pictorialismos e tentativas de construir semelhanças com a pintura e o desenho - se inseriu nas dinâmicas e estratégias da arte. Já é possível perceber uma história da fotografia e de suas relações com o circuito da arte até mesmo pela sua presença cada vez mais frequente em museus, coleções, exposições e galerias.

Possivelmente, um capítulo dessa história seja a constituição de um Departamento de Fotografia no MoMA(Nova York) na década de 1940, já que desde aproximadamente 1930 haviam esforços para estruturar uma coleção de fotografia. O gesto de colecionar, agrupar, escolher e exibir configura um regime legitimador, típico do sistema da arte e com a fotografia não foi diferente. Os curadores de fotografia do MoMA, ao longo do tempo, constituíram um conjunto expressivo de exposições e publicações. O primeiro foi Edward Steichen (1879-1973) que atuou até 1962 como curador de fotografia do Museu. Steichen realizou a importante exposição The family of the man (1955) que itinerou por diversas cidades americanas e outros países, abrindo novos sentidos para exposições compostas essencialmente de fotografias. Posteriormente John Szarkowski (1925-2007) atuou como curador entre 1962 e 1991 desenvolvendo importantes publicações sobre fotografia ainda hoje reconhecidas como Looking at photographs (1973) e Mirrors and Windows: American Photography Since 1960 (1978). Além disso, Szarkowski instituiu a exposição New photography (1980) no calendário permanente do MoMA sendo realizada, anualmente, até os dias de hoje ${ }^{1}$, revelando novos fotógrafos e artistas ligados ao domínio da fotografia. A exposição funciona, ainda hoje, como um marco das expansões acionadas no regime da fotografia.

De outro lado, o Centro de Arte Contemporânea Georges Pompidou, em Paris, desde sua fundação no fim da década de 1970,

1 As mostras anuais estão disponíveis em: https://www.moma.org/calendar/groups/1?locale $=$ en. 
contou com um departamento de fotografia tendo primeiramente Alan Sayag como curador, seguido por Peter Galassi, o qual depois de quase 30 anos no MoMa assumiu o cargo no museu francês. Esses foram alguns dos primeiros curadores ligados mais diretamente à fotografia, mas é importante trazer outros nomes que em seus trabalhos definiram as pontes, conexões e avanços da fotografia no contexto da arte.

No contexto brasileiro, é fundamental destacar Walter Zanini (1925-2013) e Frederico Morais (1936) que com a curadoria de diversas exposições associadas a textos teóricos, curatoriais e críticos, assim como na prática docente, possibilitaram a inserção da fotografia nos circuitos mais amplos em diálogo com a produção artística. Assim como Harald Szeemann (1933-2005) e Pontus Hultén (1924-2006), no cenário internacional, que também incluíram obras e proposições artísticas que tomavam as linhas de força da fotografia e da imagem como elemento intrínseco da constituição da produção artística. Integra ainda esse contexto histórico outros circuitos expressivos de uso, apropriação e expansão da fotografia em muitos outros países e regiões do mundo, constituindo narrativas específicas extremamente importantes para os redimensionamentos da história da arte.

Esses regimes legitimadores que mostramos de forma extremamente resumida, ao longo do tempo, fizeram da fotografia um rizoma na produção artística contemporânea que em suas ramificações assume desde o lugar do registro ou da fotografia vernacular até outras construções imagéticas formais e conceituais. A fotografia em sua multiplicidade em vivo contato com as dinâmicas contemporâneas da imagem.

É no cenário contemporâneo que gostaríamos de refletir sobre alguns pontos em torno da indicialidade da fotografia e de suas diversas relações com a arte. Podemos começar tomando as reflexões de Boris Groys em torno do que é o contemporâneo:

[...] o contemporâneo na verdade é constituído pela dúvida, hesitação, incerteza, indecisão - pela necessidade de reflexão 
prolongada, de um adiamento. Queremos postergar nossas decisões e ações para ter mais tempo para análise, reflexão e consideração. E isso é exatamente o que o contemporâneo é - um período prolongado, potencialmente até infinito, de adiamento. [...] A arte contemporânea pode ser vista como a arte que está envolvida na reconsideração dos projetos modernos (GROYS, 2010, p.121).

Seguindo a matriz proposta por Groys, podemos pensar a fotografia em suas relações com a arte, como um redimensionamento dos projetos modernos que se expandem por outros desdobramentos. Em um primeiro plano, o experimentalismo das vanguardas europeias (Lázlo Moholy-Nagy, Man Ray, Max Ernst e Rodchenko, entre outros) e a força de Stieglitz (1864-1946) e dos pictorialistas, em outra direção, nos Estados Unidos. Como nos mostra Jeff Wall, logo em seguida, já na década de 1920, os fotógrafos precisaram olhar para além da pintura:

Em 1920, os fotógrafos interessados em arte começaram a desviar a atenção da pintura, até mesmo da pintura moderna, para o vocabulário de seu próprio meio, e para o cinema, para descobrir sua própria natureza, descobrir-se mais uma vez, como a imagem imprevista exigida pela estética moderna (WALL, 1995, p.246) ${ }^{2}$.

A fotografia contemporânea, essa que se coloca no campo da arte, desdobrou imensamente o projeto moderno em torno dessas e de outras linhas de força, criando novos lugares e relações com as imagens que nos circundam. Esse contexto permite que a fotografia "tenha um lugar privilegiado, embora não exclusivo, para repensar seu estatuto, suas funções e modos de presença"

2 Tradução nossa de: By 1920, photographers interested in art had begun to look away from painting, even from modern painting, toward the vernacularof their own medium, and toward the cinema, to discover their own principle of spontaneity, to discover once again themselves, that unanticipated appearance of the picture demanded by modern aesthetics. 
(GONÇALVES, 2016, p. 132). Assim, tomando a fotografia no contexto da arte contemporânea, percebemos que as práticas assumem um lugar enviesado e híbrido, que de uma só vez discutem sua especificidade refletindo sobre o meio e em outras passagens se recolocam alargando cada vez mais as fronteiras e abrangências do fotográfico. Um importante reposicionamento da fotografia na contemporaneidade é justamente acionado pelas novas relações estabelecidas entre as especificidades do meio e a indicialidade.

Rosalind Krauss (1999) parte da obra do artista belga Marcel Broodthaers (1924-1976) para esclarecer novas relações que mostram como os diversos meios rearticulam suas especificidades em novas aproximações. Assumindo, logo no início de seu livro $A$ voyage on the north sea - art in the age of post medium condition (Viagem ao mar do norte - arte na era da condição pós-mídia, Thames \& Hudson, 1999) a diferença de compreensão em relação às abordagens ligadas ao meio (e às mediações, que seria assunto para outro texto). Krauss coloca especialmente a diferença em relação às fechadas formulações de Clement Greenberg que postulavam a especificidade do meio como forma de aproximação e compreensão das obras. Krauss assume outra direção.

O filme de Broodthaers The voyage on the north sea $(1974)^{3}$, ponto de partida da reflexão de Krauss, parte de um livro produzido pelo próprio artista que é recriado em filme gerando uma situação intermediária entre ambos os meios, um trânsito entre um e outro. Partindo dessa imbricada relação e para dar conta das inúmeras misturas, passagens e aproximações, especialmente nas instalações com uso da imagem em movimento, Krauss chama de "especificidade diferencial" essas formas de tensionamento e passagem entre os meios, conseguindo assim apreender uma sutil ambiguidade típica da era pós-mída. A autora ao aprofundar as reflexões em torno da condição pós-mídia, vem apontando na produção artística contemporânea importantes paradoxos, tensões

3 Disponível em https://www.youtube.com/watch?v=dQPKG1efWGg. Acesso em 24 de setembro de 2016. 
e contradições que caracterizam as questões do meio ampliando a consistência e a potência de suas abordagens iniciais. Esse gesto é nitidamente percebido em Two moments in the post medium condition (October 116, 2006) texto que analisa obras de artistas como Christian Marclay na relação entre cinema e vídeo e posteriormente em Frame by frame (Artforum, setembro, 2012) quando Krauss analisa FILM (2011) de Tacita Dean. A obra de Dean exibida na Tate Modern, em Londres, tensiona a noção de Krauss e possibilita novas abordagens, mais complexas. Krauss afirma que apesar da pouca importância do meio na produção artística contemporânea, alguns artistas, são contra essa condição e reafirmam a potência do meios com suas típicas formas de resistência, que agora passam a carregar diversas novas perspectivas. FILM aparenta ser a projeção integral da película cinematográfica $35 \mathrm{~mm}$, no entanto trata-se de adesivos que sobrepostos criam essa ilusão, acionando todas as forças que assinalam a reconfiguração dos meios. Para Krauss, "Dean, não tomou apenas o filme como suporte técnico, mas o próprio cinema como tema narrativo de sua instalação na Tate Gallery"4 (KRAUSS, 2012, p. 418).

Tomando a questão da especificidade do meio, em suas ambivalências como apontadas por Krauss na obra de Dean, podemos pensar que experimentamos um momento singular no qual é possível empreender diversas relações com os meios escapando de suas especificidades, se atrelando a elas ou mesmo problematizando suas potências e reverberações. Estamos em uma era pós-mídia na qual, os meios e suas especificidades, quando fechadas em si, tem pouca importância na formulação geral das obras. A fotografia se coloca nesse contexto da condição pós-mídia e não só assume como reinventa diversos procedimentos que possibilitam o uso dos meios em radicais aproximações e passagens.

Todo esse jogo acaba por reacender a complexa e insistente questão da indicialidade da fotografia, que Krauss também aciona ao

4 Tradução nossa para: Dean, moreover, made not only film as technnical support but cinema itself the narrative subject of her instalation in turbine hall. 
analisar a obra de Dean. Para Krauss, assim como há uma diferença, apontada por Peirce, entre a imagem fotográfica e a pintura, há uma importante diferença para Tacita Dean, entre a película fotoquímica e a imagem digital. Dean acredita em certa "natureza indicial do filme"5 (KRAUSS, 2012, p. 416), problematizando ainda mais as relações entre filme analógico e imagem digital, que para a artista seria da ordem do ícone. Tudo isso em uma obra que sintomaticamente reflete sobre o cinema, suas especificidades e as relações com as outras imagens, provocando novos posicionamentos nas relações entre os meios e a indicialidade. Em Tacita Dean (2011) a indicialidade diz respeito às características físicas do filme de apreender o real ${ }^{6}$, a especificidade do meio em movimento de resistência.

Para compreender esse jogo dos suportes e meios associados às novas formas de produção e circulação de imagens é importante perceber os potentes agenciamentos sociotécnicos que se instauram nas passagens analógico-digital (como na radicalidade de Dean e a indicialidade do filme analógico), entre muitos outros. Redes sociais, novos dispositivos de produção de imagens, conexão generalizada e diversas maneiras de fazer circular de forma massiva imagens produzidas incessantemente pelos meios de comunicação e por nós (mass self communication, como afirma Castells (2009) são novos atravessamentos que acabam por reverberar fortemente na ativação de novos processos de subjetivação, individuais e coletivos. É fundamental ver a fotografia na multiplicidade de seus agenciamentos sóciotécnicos, assim como considerar os processos de subjetivação que pilham a produção imagética atual, em um contexto pós-mídia no qual a lógica dos meios se reinventa com frequência. A ideia é estabelecer uma situação mais ambivalente 5 Tradução nossa de: [...] indexical nature of film.

6 No vídeo disponível no site da Tate, Dean revela o processo de criação de FILM e sua relação com a película fotoquímica e afirma: "I need the stuff of film as a painter needs the stuff of paint" (eu preciso da materialidade do filme como o pintor precisa da materialidade da tinta". Disponível em: http://www.tate.org.uk/context-comment/video/tacita-dean-film. Existe ainda uma longa conferência de Rosalind Krauss sobre a obra de Dean em: https://www.youtube.com/watch?v=vCU9CV7BAAk. 
entre índice e ícone, assim como outros pesquisadores, para compreender os lugares e estratégias da fotografia em sua relação com a arte. Refletir sobre uma complexificação, sobre a indicialidade para além de seus referentes diretos.

\section{A circulação, o espetáculo e a imagem ruim}

A forma-imagem que experimentamos na contemporaneidade com a ampla produção, difusão e circulação parece ir além da sociedade do espetáculo (DEBORD, 1997). Agora somos também produtores, fazemos nossas imagens correrem em escala global de distintas maneiras.

Os meios de comunicação contemporâneos e redes como Facebook, MySpace, YouTube, Second Life e Twitter dão a populações globais a possibilidade de apresentar suas fotos, vídeos e textos de uma maneira que não pode ser distinguida de qualquer trabalho de arte pós-conceitual, incluindo obras de arte com base no tempo. E isso significa que a arte contemporânea tornou-se hoje uma prática cultural em massa. [...] Se a sociedade contemporânea é, portanto, ainda uma sociedade do espetáculo, então parece ser um espetáculo sem espectadores. (GROYS, 2010, p.126).

Nesse contexto apontado por Groys aproxima-se da questão dos suportes a própria qualidade da imagem, sob uma nova ótica ainda mais complexa, já que nesse contexto o digital domina o cenário audiovisual. Ao mesmo tempo em que, cada vez mais, se faz um alarde da espantosa qualidade das imagens digitais, assistimos um certo desprezo dessa qualidade em algumas formas de produção, apropriação e circulação. Indo do filme pirata ao gif animado em 256 cores, do filme em baixa resolução do Google Play (e, portanto, mais barato no serviço de streaming) à imagem produzida por celular. Sem falar em toda uma cena de artistas, como 
observa Claire Bishop, que vem explorando os suportes analógicos: A fascinação com as mídias analógicas é um ponto de partida óbvio para um exame da relação reprimida da arte contemporânea com o digital. Manon de Boer, Matthew Buckingham, Tacita Dean, Rodney Graham, Rosalind Nashashibi, e Fiona Tan são apenas alguns dos nomes de uma longa lista de artistas atraídos pela materialidade do filme e da fotografia pré-digital. Atualmente, nenhuma exibição está completa sem alguma forma de tecnologia obsoleta e desajeitada - o barulho suave dos projetores ou o zumbido de um rolo de filme 8-mm ou 16-mm. (BISHOP, 2015, p. 38).

$\mathrm{O}$ artigo de Bishop ao refletir sobre a presença do digital na produção contemporânea acaba por acionar a questão da profusão de meios e a qualidade das imagens que habitam a contemporaneidade. Há uma relação histórica, conceitual e técnica com os meios e suportes, bem como com suas possibilidades de uso para a produção imagética, caracterizando o vigor desse agenciamento sóciotécnico.

A artista e professora da Universidade de Berlim Hito Steyerl (2009) convoca, de forma inédita, as imagens ruins, para a partir delas desenvolver uma reflexão sobre as imagens contemporâneas, suas formas de produção, circulação e as questões políticas acionadas. Steyerl primeiramente caracteriza a imagem ruim e suas ambiguidades: "imagens ruins são arrastadas pelo mundo inteiro como mercadorias ou suas efígies, como presentes ou recompensas. Elas disseminam prazer ou ameaças de morte, teorias conspiratórias ou pirataria, resistência e bestificação" (STEYERL, 2009) ${ }^{7}$. A questão dos suportes e da passagem entre eles, especialmente o lugar da película analógica na produção audiovisual, ganha um tom político na reflexão de Steyerl, desenvolvida no texto In Defense of the Poor Image ${ }^{8}$, publicado no e-flux Journal. Diferente da

7 Tradução livre de: Poor images are dragged around the globe as commodities or their effigies, as gifts or as bounty. They spread pleasure or death threats, conspiracy theories or bootlegs, resistance or stultification

8 Publicado pela primeira vez no e-flux Journal em 2009. No Brasil a tradução foi publi- 
indicialidade ligada à resistência que busca Tacita Dean na defesa da película em FILM, Steyerl vê a película como uma peça no imbricado jogo de poder que emerge da produção simbólica:

A insistência no filme analógico como único meio de importância visual influenciou muitos discursos sobre cinema, de quase todas as inflexões ideológicas. Nunca importou o fato de que essas economias afluentes da produção cinematográfica estivessem (e ainda estejam) firmemente ancoradas em sistemas de cultura nacional, em produções de estúdios capitalistas, no culto do gênio quase sempre masculino e na versão original, sendo, por isso, muitas vezes conservadoras em sua própria estrutura. (STEYERL, 2009) ${ }^{9}$

A reflexão de Steyerl traz alguns dos aspectos mais contemporâneos da produção e da circulação das imagens, mas sobretudo coloca uma carga política e social no centro do debate, enfatizando os jogos de poder ligados à produção de imagens. As ambiguidades e paradoxos da imagem permanecem, mas são amplificados pela força das novas formas do capitalismo que se coloca frequentemente nas tramas do estético e do artístico ${ }^{10}$. Além disso, os desenvolvimentos tecnológicos ligados à internet provocaram um reposicionamento brutal nas formas de distribuição. Primeiramente com as plataformas de exibição de vídeo como o Youtube, DailyMotion e Vimeo, entre outros, associados aos compartilhamentos nas diversas redes sociais que ampliaram e rearticularam a paisagem imagética contemporânea.

cado na Revista Serrote (número 9, 2015). Aqui me refiro ao texto em inglês.

9 Tradução livre de: The insistence upon analog film as the sole medium of visual importance resounded throughout discourses on cinema, almost regardless of their ideological inflection. It never mattered that these high-end economies of film production were (and still are) firmly anchored in systems of national culture, capitalist studio production, the cult of mostly male genius, and the original version, and thus are often conservative in their very structure.

10 Atualmente são diversos os nomes que tentam definir as formas mais contemporâneas do capitalismo, entre elas chama atenção "capitalismo estético", desenvolvido por Gilles Lipovetsky e Jean Serroy (2015), espécie de manual de instruções ambíguo entre revelar e criticar o modo de operação do capitalismo contemporâneo. 
Logo em seguida serviços de vídeo streaming, como a Netflix, estão ampliando ainda mais as formas de acesso a produção audiovisual, mas ao mesmo tempo inaugurando novas e inéditas formas de controle, visibilidade e segmentação de mercado. Assim como Steyerl (2009), é possível perceber que a circulação de obras raras do cinema experimental ou da videoarte que reaparecem nos circuitos imagéticos como imagens ruins sinalizam diversos aspectos. Para a autora tudo isso "revela também as condições de sua marginalização, a constelação das forças sociais que as levaram a circular como imagem ruim na internet" 11 porque perderam seu valor na "sociedade de classe das imagens". As imagens ruins servem tanto às forças do capital quanto aos gestos mais experimentais paradoxo típico das imagens na contemporaneidade.

Toda essa enorme mudança nos modos de produção e circulação de imagens se traduz na centralidade que elas alcançam cada vez mais na vida social fazendo com que, muitas vezes o referente torne-se o próprio processo de midiatização que experimentamos. Entre um meio e outro, um circuito e outro, uma narrativa e outra, uma apropriação e outra, a fotografia e o próprio domínio das imagens tornam-se criadores de um real midiatizado que transcende em muito o referente direto e real. O referente passa a ser um processo, uma relação, uma meada de sentidos com distintas cargas históricas, sociais, políticas e culturais. Novas oscilações entre gerações de imagens espalhadas em um enorme número de reproduções.

Uma obra parece sinalizar a intensidade da presença da imagem na vida social. Em 24 hours in photos (24 horas em fotos) Erik Kessels distribui nos espaços expositivos montanhas de imagens impressas de todas as fotos postadas em determinada rede social em um dia qualquer. O trabalho é ambíguo, e talvez daí venha sua potência. A obra, assim como o texto que a apresenta no site, parece enaltecer ao mostrar o volume de imagens que conseguimos

11 Tradução livre de: it also reveals the conditions of their marginalization, the constellation of social forces leading to their online circulation as poor images. 
produzir:

Graças à riqueza dos sites de compartilhamento de imagens e à disponibilidade das câmeras digitais, o mundo está sujeito a uma avalanche de novas fotos todos os dias. Para " 24 hours in photos", um único dia foi escolhido, e as imagens desse único dia impressas. O resultado foram montanhas de fotos, que vão do chão da galeria ao teto ${ }^{12}$.

Essa enorme quantidade de fotos assusta. Primeiro pelo caráter efêmero da imagem que circula: Arquivos que se movem de uma rede à outra e depois podem se perder na enorme profusão de imagens, meios e memórias. Uma sucessão de "agoras" imediatos, muitas vezes ordinários, uma acumulação em vão de tempo presente, sem qualquer futuro. Uma imagem banal que muitas vezes só serve para documentar ou marcar a urgência sem densidade do tempo presente. Na obra de Kessels (2011) o referente de cada uma das imagens parece não ter sentido. Se houver, seu sentido é o excesso, o transbordar das imagens pelo espaço, não como referente e marca do real, mas como volume de registros.

Assim como em Kessels observamos outras obras que vamos comentar a seguir, que ampliam, complexificam e expandem a noção de referente, dando um novo contexto para a indicialidade da fotografia contemporânea.

\section{Outras indicialidades}

Ao observar alguns gestos na produção artística contemporânea é possível perceber como há uma tensionamento na indicialidade, provocado pelo modo como fotografia, meio e vida social se enfrentam compartilhando e acionando um contexto povoado de imagens. Acreditamos que na indicialidade da fotografia reverbera as tramas da enorme quantidade de referências imagéticas que ao longo do tempo experimentamos em processos

12 Disponível em http://www.kesselskramer.com/exhibitions/24-hrs-of-photos 
de midiatização cada vez mais avançados que acionam nossas formas de interação.

Vamos elencar alguns exemplos nos quais a indicialidade da fotografia pensa sobre o meio, a imagem e aos circuitos de imagens que experimentamos. Esses exemplos operam como pontos de uma cartografia mais ampla que delimita esse expansivo conjunto de relações e estratégias que caracterizam a fotografia contemporânea e suas relações com o domínio mais ampliado das imagens.

A obra de Pedro Motta vem se tornando um território aberto aos jogos de sentido que a fotografia pode produzir em seus desdobramentos, apropriações e formas de inserção. Em sua última exposição Estado da natureza (2016), Câmerasete - Casa da Fotografia de Minas Gerais - Belo Horizonte) Motta tensiona as relações com a natureza em fotografias que "são o resultado de várias estratégias: a representação direta, a apresentação material e a construção ficcional, usualmente combinadas para produzir imagens misteriosas, de grande força expressiva" (ROCA, 2016). Apesar da força dos trabalhos desta exposição mais recente que traz sofisticadas intervenções nas imagens enfatizando um traço quase catastrófico da natureza, gostaríamos de retomar a série anterior Caixa d'água ${ }^{13}$ premiada no $14^{\circ}$ Salão do Museu de Arte Modena da Bahia (2007) e publicada em seu livro Temprano (Edição do autor, 2010). A série mostra um conjunto de imagens em preto e branco com rigorosas e bem elaboradas composições formais, mostrando diversos tipos de caixas d'água. Algumas são alteradas digitalmente gerando construções impossíveis, com enormes caixas d'água sustentadas por canos finos ou por apenas um estreito pilar. A questão aqui não é exatamente mostrar as caixas d'água como forma de registro ou documentação, mas reconhecer um lastro histórico-conceitual das séries produzidas pelo casal Becher (Bernhard Becher 1931-2007 e Hilla Becher 1934-2015), na década de 1970. A indicialidade não se refere exatamente ao real

13 A série está disponível no site do artista em: http:/www.pedromotta.net/v1/en/obra/ caixa-dagua/. 
que tocou a imagem, mas ao que ela parece comentar se abrindo para outros sentidos, como se na apropriação quase irônica dos Becher, emergisse o índice dessa imagem.

Outros artistas como Kent Rogowski ${ }^{14}$, que expôs no Brasil na primeira edição do Festival Internacional de Fotografia de Belo Horizonte (FIF), em 2013, reconstrói os sentidos dando novos contornos ao real que tangencia a imagem, como se fosse uma segunda camada que recobre e por isso distorce tudo levando a um novo estrato. O meio desliza e parece possibilitar a ação de construir a imagem a partir de algo, como quebra-cabeças ou capas de livros, que apontam para arranjos sociais, expressos em formas simbólicas quase desgastadas de apreensão dos índices do real. Rugowski aciona outros modos de construir uma indicialidade que se expande para além da imagem que vemos, nos levando a pensar mais nas lógicas das imagens do que no real especificamente. Não são apenas livros ou quebra-cabeças, mas uma construção imagética que revela um conjunto de valores culturais, padrões e toda uma constelação de atravessamentos produzidos pelas imagens nas relações com os sujeitos.

Nas duas séries apresentadas no FIF, Rogowski acionou repertórios imagéticos próprios que carregam em si inúmeros processos de significação pelo modo como se inserem na dinâmica social. As capas de livros de auto-ajuda, assim como as frases e imagens de capas de romances sustentados pelo título da série Everything I wish I could be (Tudo o que eu queria ser) acionam algo muito maior fora da imagem. Diz respeito, sobretudo, ao modo como alguns elementos visuais e textos são recorrentes nessas mensagens de auto-ajuda, nos fazendo deslocar das capas para pensar nas formas subjetivas e no lugar desses discursos. Ainda na chave da ironia, Rogowski apresentou a série Love = Love $($ amor $=$ amor) composta por imagens montadas com peças de quebra-cabeças misturando as bucólicas e quase irreais paisagens

14 A série está disponível no site do FIF em: http://www.fif.art.br/2013/2014/08/29/kent-rogowski/. 
com imagens de flores coloridas, ambos padrões típicos desses passatempos. Os fragmentos de imagens das peças mudam, mas os padrões de encaixe não mudam quando os quebra-cabeças são feitos pelas mesmas fábricas. Essa jocosa descoberta de Rugowski permitiu fundir imagens de forma rudimentar em composições surpreendentes revelando com o gesto os modos como as imagens se tornam clichês e meras repetições, moldes. A indicialidade de algumas imagens na contemporaneidade, assim como os quebracabeças de Rugowski, não importa mais, mas sim o jogo que podemos fazer com os mesmos moldes.

$\mathrm{Na}$ mesma edição do Festival a relação entre o meio e a indicialidade apareceu em outros trabalhos que indicavam ainda mais complexidade. Como na série Most Popular of All Time (Mais popular de todos os tempos) apresentada pela dupla MacdonaldStrand (Clare Strand e Gordon Macdonald). A dupla toma imagens extremamente populares da cultura midiática global como a queda de pessoas no World Trade Center, a imagem de Che Guevara, Einstein colocando a língua para fora ou as manifestações na Praça da Paz Celestial na China reduzindo-as a traços em preto e branco. Alguns desses traços trazem números que, como no tradicional passatempo, nos permitem ligar os pontos na ordem para ver emergir a figura que completa a imagem. Essas imagens da dupla se referem muito mais aos lugares que passaram a ocupar no imaginário global, do que efetivamente se reduzem ao traço indicial que as organiza. O índice aqui indica um suntuoso conjunto de relações entre imagens, meios e formas de circulação que levam a novos contornos das relações sociais e políticas mediadas pelas imagens, pelas fotografias que possibilitaram essa construção.

Além de colocarem as imagens na tradicional forma expositiva do cubo branco da galeria, os artistas deixam diversas das imagens impressas no mesmo papel comum que as cópias emolduradas, ao contrário das impressões em papeis especiais, para que o público recolha as imagens e possa juntar os pontos, desmanchando assim as formas mais recorrentes de exposição e de 
relação entre visitantes e obras no circuito da arte.

\section{Considerações finais}

Nesses poucos exemplos comentados podemos perceber que o referente oscila dinamicamente entre o real, as outras imagens, os diversos procedimentos de apropriação e referência à história da arte e às forças da midiatização. Uma indicialidade com novos contornos, ambivalências e tensões produzida de um lado pela presença marcante das imagens nas mediações de toda ordem na vida social e de outro pela multiplicidade que a fotografia aciona no domínio da arte construindo novos jogos de sentido em tramas cada vez mais complexas.

Trata-se agora de uma nova etapa na qual as imagens operam em direto contato com novas lógicas de produção, circulação, mediação e apropriação inseridas fortemente nas dinâmicas sociais. Vamos do meme difundido em rede que solicita um sentido para a imagem que sempre se orienta para as dinâmicas sociais até o domínio da arte que passa a lidar com novas relações de sentido instauradas pelas imagens em suas diversas ocorrências e usos.

\section{Referências}

CASTELLS, Manuel. Communication Power. New York: Oxford University, 2009.

BISHOP, Claire. Divisão digital. Revista Eco pós. [on-line]. Rio de Janeiro, v, 18, n. 1, 2015. Disponível em: < https://revistas.ufrj. br/index.php/eco_pos/article/view/2391>. Acesso em: 12 set. 2016. DEBORD, Guy. A sociedade do espetáculo. Rio de Janeiro: Contraponto, 1997.

GONÇALVES, Fernando. Inatualidade e anacronismo na 
fotografia contemporânea. Revista Galáxia, São Paulo, n.33, p.131-144, 2016.

GROYS, Boris. Camaradas do tempo. Caderno SESC Videobrasil, São Paulo, v. 6, n.6, 2010.

KRAUSS, Rosalind. A voyage on the north sea Art in the age of the post-medium condition. Nova York: Thames \& Hudson, 1999. KRAUSS, Rosalind. Clouse-up: Frame by frame. Artforum, Nova York, v. 51, n 1. Set., 2012.

KESSELS, Eric. 24 hours in photo. 2011. Disponível em: $<$ http:// www.kesselskramer.com/exhibitions/24-hrs-of-photos>. Acesso em: 16 set., 2016.

LIPOVETSKY. G.; SERROY, J. A estetização do mundo: viver na era do capitalismo artista. São Paulo: Companhia das Letras, 2015.

ROCA, José. Estado da natureza - Pedro Motta. Catálogo da exposição. Câmerasete - Casa da Fotografia de Minas Gerais, Belo Horizonte, 2016.

STEYERL, Hito. In defense of poor image. E-flux journal, 10 Nov. 2009. Disponível em: <http://www.e-flux.com/journal/indefense-of-the-poor-image/>. Acesso em: 4 jan. 2016.

WALL, Jeff. Marks of indifference: Aspects of photography in, or as, conceptual art. In: GOLDSTEIN, Ann; RORIMER, Anne. Reconsidering the object of art, 1965- 1975. Los Angeles Museum of Contemporary Art, 1995. 